\title{
Uma perspectiva interacionista em educação à distância na área de linguagem
}

(An interaction perspective in distance learning in the language area)

RAQUEL MARQues ViLLARDi

Universidade do Estado do Rio de Janeiro

Cleia Santos Rodrigues

Universidade do Estado do Rio de Janeiro

Marta Cardoso de Lima da Costa Rego

Universidade do Estado do Rio de Janeiro

CRISTIANE Fallah dE AgUILAR

Universidade do Estado do Rio de Janeiro

Daniel do Vale Gonçalves Pereira

Universidade do Estado do Rio de Janeiro

THIAGO LOPES SCHETTINI

Universidade do Estado do Rio de Janeiro

Juliana Maria Alves de Carvalho

Universidade do Estado do Rio de Janeiro

ESTER OLIVEIRA

Universidade do Estado do Rio de Janeiro

RESUMO: Este trabalho objetiva buscar caminhos que viabilizem a melhoria do ensino de linguagem no sistema educacional brasileiro na escola básica. A forma encontrada de atender a demanda de formação dos professores com vistas ao desenvolvimento lingüístico de seus alunos, no campo da leitura e da escrita foi desenvolver um suporte didático - metodológico computacional múltiplo para formação continuada à distância. Delineamos uma proposta interativa na perspectiva da construção do conhecimento. Foi desenvolvido um protótipo de curso que foi testado em bancada, objetivando também, a formação dos tutores como primeiros alunos do curso. Para tal escolhemos ferramentas de interação com base em estudos de 
Raquel Marques Villardi, Cleia Santos Rodrigues, Marta Cardoso de Lima da Costa Rego...

aplicabilidade e funcionalidade. Trabalhar com educação à distância nessa perspectiva diferenciada, amplia as possibilidades de atingir o corpo docente da rede pública num país de dimensões continentais como o Brasil, onde as fronteiras e limitações físicas e metodológicas da escola precisam ser rompidas.

Linguagem, Educaçã - Tecnología - Tutor - Comunicação - Interatividade

ABSTRACT: This work aims the search for wavs to enhance language learning in the elementary school in Brazilian educational system. The way found to attend the demand of teachers' formation aiming their students' linguistic development, in the fields of read and write was to develop a didatic support - methodological computational multiple to distance continuous formation. We delineated an interactive proposition on the perspective of knowledge building. Developed a prototype of the course that was workbench tested, also aiming, the formation of the tutors as first students of the course. To this we chose interaction tools based in applicability and functionality studies. Work with distance learning in this differentiate perspective, amplify the possibilities to touch the teaching body of the public system in a country with the continental dimensions like Brazil, where the borders and physical and methodological limitations of schools must be broken up.

Language - education - technology - Tutor - Communication - Interactivity.

A dependência que existe entre o desempenho lingüístico e o processo de aquisição de conhecimentos reside no fato de que a linguagem corresponde ao principal instrumento para a codificação e veiculação do saber formal transmitido pela escola. Problemas de compreensão afetam diretamente o desempenho da criança, não só no que diz respeito especificamente ao estudo da língua, mas em todas as áreas do conhecimento, e durante toda a sua escolaridade.

A situação se agrava na contemporaneidade, face à pressão dos novos códigos de linguagem advindos da cibercultura, por um lado, e do estabelecimento de novas relações no que tange às formas apropriação do saber, por outro.

Não há como negar, também, que o professor que trabalha com língua portuguesa, vem recebendo, sistematicamente, no ensino fundamental, um corpo discente que apresenta baixíssimo rendimento tanto na recepção quanto na produção de textos. Tal desempenho em língua portuguesa repercute, conseqüentemente, no das demais disciplinas, já que é através da linguagem que se dá a decodificação / codificação de toda a informação veiculada pela escola.

Apesar de os resultados do trabalho com a linguagem dependerem de uma série de fatores - políticos, econômicos, sociais, psicológicos, lingüísticos, metodológicos e pedagógicos - sua renovação, visando ao melhor desempenho escolar dos alunos, depende, em grande parte, do esforço do professor. Mas muitas são as dificuldades enfrentadas por ele no aperfeiçoamento lingüístico de seus alunos, no desenvolvimento de habilidades de recepção e produção de textos, as quais se acentuam na medida em que o professor não dispõe de conhecimento suficiente nem para compreender como se dá o processo de estruturação do conhecimento no discurso, nem para desenvolver de modo eficaz as habilidades dos alunos no campo da leitura e da escrita. 
A origem dessa situação pode ser determinada, entre outros casos, nos cursos de formação de professores, onde, salvo poucas exceções, o estudo científico da língua se restringe a conceituações gerais e à discussão de modelos teóricos raramente aplicados em análises da língua, situação em que a literatura acaba apagada frente a uma perspectiva de aplicabilidade ao ensino da gramática.

Lacunas referentes a aspectos essenciais da psicolingüística (teorias e mecanismos de aquisição da linguagem, etapas no desenvolvimento da linguagem), da sociolingüística (variações no uso da língua) e lingüística textual (mecanismos determinantes da textualidade) e da Teoria da Literatura (Teoria da Recepção) são comuns nos currículos dos Cursos de Formação de Professores. Mesmo na área da Literatura Infanto-Juvenil, muito pouco se instrumentaliza o professor, e menos ainda se o sensibiliza para a necessidade de uma abordagem mais aprofundada do texto literário dirigido, prioritariamente, para crianças e adolescentes. Desta forma, o professor que trabalha com a Língua Portuguesa pouco (ou quase nada) conhece sobre processos psico-sociolingüísticos e discursivos inerentes à recepção e à produção de textos, ou mesmo recebe a informação básica do acervo existente na área da Literatura Infanto-Juvenil.

Este quadro é agravado ainda mais pelo fato de que a formação do professor, alicerçada no aspecto do domínio do conteúdo, acaba determinando que fiquem em segundo plano (quando ficam) todos os aspectos referentes à metodologia do ensino da Língua e da Literatura Infanto-Juvenil.

Assim - na medida em que o texto literário traz embutidos em si por um lado uma questão estética e, por outro, uma estrutura de linguagem específica, imagética, que torna sua decodificação, por natureza, mais difícil - o habitual é vermos a escola tratar o texto literário com a mesma superficialidade com que trata do texto informativo do jornal, por exemplo.

Desta forma, retira-se do aluno a possibilidade de desenvolver a habilidade de ler os significados não-evidentes de um texto, fato que se refletirá, genericamente, na sua capacidade de "ler o mundo», levando-o a se contentar com aquilo que parece, não necessariamente com aquilo que é.

Por considerar válidas as contribuições da Lingüística Aplicada e da Teoria da Literatura ao trabalho com a linguagem, os professores que integram a equipe deste projeto têm desenvolvido estudos que visam tanto a alargar o conhecimento teórico relativo à compreensão dos processos cognitivos inerentes à recepção e produção de textos, quanto a investigar mecanismos que viabilizem a utilização deste conhecimento diretamente na sala de aula.

Os conhecimentos teóricos da Lingüística Aplicada e da Teoria da Literatura, quando utilizados no ensino da linguagem, possibilitam o abandono de uma postura empírica e reduplicadora, e a instauração de uma realidade onde o trabalho se 
sedimente sobre sólidas bases científicas. Tal perspectiva vem gerar, conseqüentemente, novas práticas, através da redefinição de objetivos, da implementação de novas estratégias de ensino e da elaboração de material didático, cientificamente subsidiado e adequado à realidade lingüística do aluno.

As sociedades atuais têm se tornado mais complexas a cada dia. Tal complexidade, aliada à rapidez dos avanços tecnológicos tornaram inviável a tarefa de educar alguém, sendo necessário desenvolver no aluno, habilidades mentais e cognitivas, que lhe permitam lidar com o novo, criando uma perspectiva de construção do conhecimento a partir da auto-gestão.

Soma-se a essa primeira questão, a impossibilidade de formação profissional fora dos grandes centros, o que, num país de grande dimensão territorial como o Brasil, transforma-se num importante fator de exclusão social, que está no âmago das distorções estruturais presentes em nosso processo de desenvolvimento . Dificuldades de toda ordem se apresentam no percurso daqueles que se propõem a romper a distância para estudar, numa luta cotidiana entre o homem e seus limites, que, quase sempre, culmina num abandono frustrante.

Nos últimos 30 anos, foi feito um esforço considerável no sentido de universalizar a educação, em termos de ensino fundamental, esforço que elevou a taxa de escolarização nacional, hoje, ao patamar de $91 \%$, - mais de 25 pontos acima da que tínhamos na década de $70^{1}$. Os números, no entanto, não expressam uma mudança significativa na qualidade da educação oferecida, nem tampouco tal aumento se traduziu como melhoria na qualidade de vida do cidadão brasileiro:

Embora a importância da educação seja unanimemente reconhecida, são ainda pouco satisfatórios os resultados do esforço educacional realizado nos últimos anos, o que fica evidente nas altas taxas de repetência e nos baixos níveis de qualidade do ensino. Não se trata, no entanto, apenas de dar mais recursos financeiros à educação. A baixa eficiência do sistema educacional a baixa qualidade do ensino devem ser enfrentados através de ações coordenadas dos governos federal, estaduais e municipais que confiram prioridade à educação fundamental, à elevação do nível de escolaridade da população de baixa renda e à melhoria da qualidade do ensino (grifo nosso) ${ }^{2}$.

Claro que é importante termos todas as crianças na escola. Mas isso, por si só, não basta. Alguns mecanismos de manutenção do aluno na escola, implantados em vários pontos do país ${ }^{3}$, acabam por atacar o efeito sem se deter nas causas que complexificam os fenômenos da repetência e da evasão escolar. Universalizou-se

\footnotetext{
Castro, M. H. G. (1999) p. 69

Relatório sobre o Desenvolvimento Humano do Brasil - PNUD / Programa das Nações Unidas para o Desenvolvimento - http://www.undp.org.br/rdhb1-7.htm

Refiro-me a Programas como o «Bolsa Escola» e à implantação de classes de aceleração e de mecanismos de promoção automática, por exemplo.
} 
a matrícula na escola, sem se universalizar a escola - que se mantém presa a paradigmas seculares, quando era dirigida apenas a uma elite, e que, portanto, tinha como valor fundamental uma cultura enciclopédica, assentada sobre a memorização de dados esparsos.

Assim, as conseqüências de um sistema pseudamente voltado para a educação acessível a todos se fazem sentir sobre alunos e professores, embrenhados ambos num processo que, à medida em que universaliza o acesso à escola, vai esvaziando, paulatina e perigosamente, o valor da educação;

um sistema que se perde em suas próprias esquinas, (...) dentro do qual professores atônitos ou descrentes ou aflitos ou cansados ou bem-intencionados ou miseráveis ou tudo isso se vêem sem saber o que fazer ${ }^{4}$.

Os mecanismos que viabilizam o resgate da atividade educacional - enquanto atividade dotada de um sentido, endogenamente relevante para professores e alunos - passam, necessariamente, pela possibilidade de adequação do que se aprende (e do que se ensina) na escola a um mundo cujas exigências ultrapassam em muito o conhecimento vitrificado.

Dada a relação entre pobreza, analfabetismo, repetência e evasão escolar, é necessária a formulação de políticas dirigidas aos contingentes populacionais mais pobres. Para assegurar a melhoria da qualidade do ensino, é preciso dotar as escolas de instalações, equipamentos, material didático e capacidade docente, assim como instituir um processo contínuo de inovação pedagógica, a avaliação permanente dos resultados e estímulos para melhor desempenho de professores e alunos 5 .

E enquanto não nos debruçarmos em propostas capazes de transformar a vida escolar da criança e do adolescente em algo cujo valor lhe seja visível, habilitando os docentes a enfrentarem o desafio de sua própria redimensão, certamente estaremos escamoteando o problema, adiando o momento da evasão, distribuindo certificados sem qualquer valor individual ou social.

Dentro desse cenário, a utilização de recursos tecnológicos no espaço educacional não pode significar uma simples transformação do papel em tela de monitor - de TV ou de PC. A incorporação dos avanços científicos e tecnológicos interfere na vida cotidiana, exigindo o domínio de novas linguagens tornadas operacionais pela tecnologia - o que traz severos impactos tanto sobre a cultura quanto sobre as formas de produção e de apropriação dos saberes.

Como se sabe, a Lei de Diretrizes e Bases para a Educação Nacional (Lei 9394/96), estabelece, em seu Artigo 62, que a formação docente para atuar na educação básica deverá ser feita em curso superior. $\mathrm{O}$ último censo da educação

\footnotetext{
${ }^{4}$ Villardi, R. (2000) p. 9

${ }^{5}$ Relatório sobre o Desenvolvimento Humano do Brasil - PNUD / Programa das Nações Unidas para o Desenvolvimento - http://www.undp.org.br/rdhb1-7.htm.
} 
Raquel Marques Villardi, Cleia Santos Rodrigues, Marta Cardoso de Lima da Costa Rego...

brasileira $^{6}$ demonstra que, embora as diferenças regionais sejam gritantes, e que mais da metade dos docentes da Região Sudeste já tenham esse nível de formação, a demanda por cursos que permitam o atendimento do preceito legal atinge, ainda, níveis quase alarmantes.

Tabela. Quantitativo de docentes das redes municipais e estaduais do Estado do Rio de Janeiro, por nivel de formação:

\begin{tabular}{|c|c|c|c|c|c|}
\hline \multirow{2}{*}{ Rede } & \multirow{2}{*}{$\begin{array}{l}\text { Nivel de } \\
\text { ałuaçã̃o }\end{array}$} & \multicolumn{3}{|c|}{ Grau de Formação } & \multirow{2}{*}{ TOTAL } \\
\hline & & $1^{\circ}$ grau & $2^{\circ} \mathrm{grau}$ & $3^{\circ} \mathrm{grau}$ & \\
\hline \multirow[t]{3}{*}{ Estadual } & $1^{\underline{a}}$ à $4^{\underline{a}}$ & 7 & 5.982 & 2.160 & 8.190 \\
\hline & $5^{\mathrm{a}}$ à $8^{\mathrm{a}}$ & 10 & 2.739 & 9.062 & 11.872 \\
\hline & total & 17 & 8.721 & 11.222 & 20.062 \\
\hline \multirow[t]{4}{*}{ Municipais } & ed. infantil & 69 & 5.811 & 2.913 & 8.824 \\
\hline & $1^{\mathrm{a}}$ à $4^{\mathrm{a}}$ & 55 & 10.860 & 6.722 & 17.694 \\
\hline & $5^{\mathrm{a}}$ à $8^{\underline{a}}$ & 9 & 1.047 & 12.461 & 13.576 \\
\hline & total & 133 & 17.718 & 22.096 & 40.094 \\
\hline TOTAL & & 150 & 26.439 & 33.318 & 60.156 \\
\hline
\end{tabular}

Fonte: MEC / INEP - Censo do Professor de 1997

Os dados do Censo apontam, como se vê na Tabela 1, que só no Estado do Rio de Janeiro, e considerada aí apenas a rede pública, são quase 27 mil docentes que precisarão ser formados em nível de graduação, para que se dê, até 2006, atendimento ao que preconiza a LDB. Portanto, é necessário que se concretizem as condições para o atendimento a tal contingente do corpo docente.

Mas o que se coloca, aqui, não é a mera certificação desses docentes. Nosso compromisso - como servidores públicos e como cidadãos - não poderia ser outro senão o de formar, independentemente do nível dessa formação, profissionais capazes, aptos a enfrentar o desafio de educar a população mais pobre, aquela para a qual, apesar de estar na escola, o acesso ao mundo que se abre com a cultura letrada permanece vetado.

O questionamento da escola convencional que começara no início do século e se acentuara nos anos 60 com a corrente de idéias defendidas por Ilich e Reimer, ao qualificar o sistema escolar como «fechado», "monopolizador» e «marginalizador», deu origem a um movimento inovador para incorporar novos métodos e modalidades de ensino que rompessem as limitações físicas e

\footnotetext{
${ }^{6}$ INEP, 1999. http://www.inep.gov.br

Os valores da coluna «Total» não expressam exatamente a soma das colunas anteriores, porque omitimos a coluna referente ao número de docentes que «não informaram» a sua formação.
} 
metodológicas da escola, resultando em uma mudança de enfoque que inseriu o mundo tecnológico no cotidiano da escola, o que nos parece irreversível. Nessa mesma perspectiva, Humberto Eco ${ }^{8}$ reforça a importância de uma escola que desenvolva uma nova competência, que se fundamenta numa das habilidades cognitivas básicas: a da seleção.

Tal exigência confere à escola a necessidade de um caráter dinâmico, onde o valor maior recai sobre a interação, sobre o contato com a multiplicidade de visões, numa dimensão educativa de culto à tolerância, fundamental para o próprio exercício da cidadania.

Diante disso, não faz qualquer sentido manter a escola estruturada sobre o uso monocórdico do giz, assessorado, quando muito, pelo livro didático ou pela fotocópia (impossível resistir à facilidade da máquina, quando não afeta práticas seculares...) - e muito menos condenar o aluno à estaticidade do ouvir e do reduplicar.

Em outras palavras, por mais que se venha investindo em mudanças de enfoque, e por mais que isso seja urgentemente necessário, o aproveitamento dos recursos tecnológicos se traduz, ainda, como mero adereço na ação educativa, a qual, para além dos discursos (já quase velhos) do foco no aluno, continua centrada na figura de um professor detentor do saber, cuja função é ensinar ; se o aluno vai aprender é outro problema...

Se, no entanto, é isso o que acontece na imensa maioria das escolas brasileiras, não é por outra causa senão a de que o professor brasileiro continua sendo formado para «dar conta» de um conteúdo, que ele deve saber para poder transmitir ao aluno. Perde-se o espaço do exercício da divergência, da leitura crítica, da observação apurada; perde-se o espaço do desenvolvimento de habilidades inestimáveis para a vida do homem contemporâneo; perde-se o espaço de ampliação de competências comunicativas em diferentes linguagens. E pior: perde-se um tempo que não será recuperado jamais.

Investir, hoje, numa formação docente alicerçada sobre múltiplas linguagens e apoiada no uso conseqüente de recursos tecnológicos, portanto, para além de qualquer argumento de ordem econômica ou política, é uma decisão que se sustenta sobre um argumento quase pueril: o de que só será capaz de implementar uma perspectiva de educação voltada para o homem contemporâneo o docente que tiver tido a chance de experimentá-la.

Nossos alunos necessitam saber ler o que vêem e também produzir, expressarse no mundo audiovisual e virtual, precisam tornar-se leitores proficientes (Villardi, 1996), ou seja, leitores críticos, capazes de se apropriarem daquilo que lêem e de estabelecerem diversas relações com o objeto da leitura, colocando-os em diálogo

\footnotetext{
${ }^{8}$ Eco, H.(1997)
} 
Raquel Marques Villardi, Cleia Santos Rodrigues, Marta Cardoso de Lima da Costa Rego...

com o mundo que os cerca. Nessas circunstâncias, é preciso pensar numa forma de levar educação às massas que estão distantes dos centros urbanos, com um padrão de qualidade que seja igual ou melhor que o da educação ministrada nas boas escolas de educação presencial. A educação à distância é uma alternativa que se torna a cada dia mais popular, pela sua utilização nos setores educacionais públicos e privados.

O conceito de ensino à distância não é novo, e, ao contrário do que habitualmente se pensa, essa é uma modalidade em que o Brasil vem atuando há várias décadas. Ao longo desse tempo, o enfoque do ensino à distância se altera, de acordo com a finalidade e com a mídia privilegiada em cada momento de intervenção.

Iniciado com o uso da correspondência, pelo Instituto Universal Brasileiro, que tinha como objetivo a formação de técnicos, passando pelo rádio e pela TV, que se dedicaram preferencialmente à suplência, o ensino à distância, no Brasil, sempre esteve associado à formação profissional ou escolar de trabalhadores de classes populares, que não tinham acesso às esferas formais de escolarização; um ensino que, ainda hoje, em nada se assemelha à formação dos bacharéis, feita nas universidades. Sempre ensino; nunca educação. Estruturado sobre «ação sistemática e conjunta de diversos recursos didáticos, apoio de uma organização, e tutoria, propiciando a aprendizagem independente e flexível dos alunos» ${ }^{9}$, o ensino à distância se caracterizou, entre nós, pelo predomínio da informação sobre a formação, veiculada por meio de material didático de caráter instrucional, muitas vezes sob o enfoque da instrução programada.

Assim, no ensino à distância, além de a aproximação entre professor e aluno se dar por intermédio de um texto - ou seja, de uma mensagem, cujo significado está sujeito a interferências de um sem-número de fatores, por mais cuidadosa que seja sua elaboração - a interação, já precária, fica adstrita, no máximo, ao binômio professor (tutor) / aluno.

A necessária distinção entre ensino e educação à distância demarca, portanto, os limites de uma ação educativa (da qual o ensino é apenas uma parte), exercida num espaço de interação constante, no qual se estrutura o processo ensinoaprendizagem. Nessas condições, busca-se o desenvolvimento integral, autoestruturado, autogerenciado e auto-direcionado do indivíduo, possível a partir de uma relação dialógica que se mediatiza pela interação múltipla ${ }^{10}$.

Vista sob esse prisma, a educação à distância ultrapassa as fronteiras da contraposição à educação presencial e amplia-se para uma perspectiva de comunicação múltipla entre sujeitos em ambientes distintos, promovida a partir

\footnotetext{
9 García Aretio, L. (1994). p. 28

${ }^{10}$ Landim, C. (1999).
} 
Uma perspectiva interacionista em educação à distância na área de linguagem

de um processo sistemático, cuja vantagem maior é a de respeitar o ritmo individual da aprendizagem. Se até então as condições para essa interação múltipla eram quase inviáveis, por meio da telemática " passou a ser possível construir ambientes virtuais de interação multidirecional, que permitem a colaboração e a cooperação entre os sujeitos envolvidos, embora preservando a característica básica de o aluno ser o protagonista de seu próprio aprendizado. E os avanços tecnológicos não param:

Now, in the late 90s, we see the blending of various technologies in the distance learning delivery system that will be used in the new millennium. We are witnessing, and helping to bring about, the multimedia approach that incorporates sound, picture, text, data, and computer programs - directly into the home or office. The television set of tomorrow will be connected to the Internet via high-speed cable or wireless connection with instant access, graphically, around the world. When the system beeps, the TV program will fade and mute to be replaced by the caller. In full color and full motion, your call will proceed almost as if you are sitting across from one another. If it is a class, the class member speaking will be shown on your screen. Voice recognition will perform many of the functions that a mouse does today ${ }^{12}$.

A discussão acerca da utilização ou não de recursos tecnológicos na EAD não pode ficar adstrita a fatores econômicos, nem ser lida como uma questão de moda, embora existam experiências de monta tanto com a adoção de mídias tradicionais quanto com o incremento de mídias eletrônicas ${ }^{13}$. Devem, ao contrário, ter como referência o tipo de objetivo que se pretende atingir.

Nossas pesquisas ${ }^{14}$ vêm demonstrando que o uso de suportes informatizados tem forte impacto sobre o nível de envolvimento do aluno com o objeto da aprendizagem, contribuindo largamente para a melhoria de seu desempenho.

Com o aprimoramento da tecnologia da comunicação, surgiu também a expectativa de que novos materiais de apoio viessem a ser incorporados na educação

\footnotetext{
"Telemática - simbiose entre os recursos advindos das telecomunicações e da informática

${ }^{12}$ Sherry, L. (1999) on line. «Hoje, em final dos anos 90, vemos a mistura de várias tecnologias em ensino à distância que serão utilizadas no novo milênio. Estamos testemunhando e auxiliando o surgimento de uma abordagem multimídia, que incorpora som, imagem, texto, dados e programas de computador, diretamente para dentro de casa ou do escritório. A televisão do futuro estará conectada à banda larga da internet, ou por conexão sem fio de acesso instantâneo, graficamente, em qualquer lugar do planeta. Quando sistema avisar, a transmissão televisiva ficará sem som e imagem para receber a entrada de dados. A cores e com movimento, a chamada será realizada como se você estivesse sentado em frente ao outro. Se for uma sala de aula, o aluno falará com outro em um lugar remoto, pela tela. Sistemas de reconhecimento de voz cumprirão muitas das funções que hoje são realizadas pelo mouse».

${ }^{13}$ A UNED, na Espanha, que só ministra cursos à distância, atende a 150 mil alunos de graduação, sem utilização de recursos computacionais; a Open University, na Inglaterra, pioneira nessa modalidade de ensino, e que oferece cursos em todo o mundo, não prescinde do uso de recursos tecnológicos.

${ }^{14}$ Villardi, R. (2000), Villardi, R. \& senna, L. A. G. (1999), Villardi, R. Silveira, E. (1998).
} 
Raquel Marques Villardi, Cleia Santos Rodrigues, Marta Cardoso de Lima da Costa Rego...

à distância. Os novos recursos tecnológicos vêm modificando estruturalmente os ambientes de aprendizagem. Tal alternativa, como era de se esperar, tem sido alvo de muitas críticas, que de alguma forma reduplicam as trazidas por tecnófobos (ou apocalípticos ${ }^{15}$ ), que durante décadas viram nessa opção uma via de desmoronamento da cultura, com conseqüências destrutivas para a própria dimensão humana. Assim, a resistência de considerável parcela da humanidade à inovação tecnológica tem encontrado eco em teóricos de peso, como Baudrillard ${ }^{16}$ e Sfez ${ }^{17}$, que vaticinam um futuro negro para a humanidade, por influência das máquinas. Não se pode perder de vista, no entanto, que todo grande avanço tecnológico só se impôs, culturalmente, depois de resistências e pesadas críticas.

A argumentação contra as transformações advindas da técnica não é privilégio do nosso tempo, mas já estava presente no pensamento de grandes filósofos da Grécia antiga. (...) Nos textos de Platão foram apresentados vários argumentos contra a escrita, que se sedimentava naquele momento da história grega ${ }^{18}$.

$\mathrm{O}$ principal fundamento da crítica dos gregos à escrita residia no fato de que o homem, escrevendo, deixaria de usar seu potencial de memória, provocando, assim, um embotamento mental. No entanto, nem toda a argumentação grega foi capaz de evitar a incorporação da nova técnica à cultura. E assim, cedendo ao inevitável, o homem aquiesceu à escrita, como aquiesceria, mais tarde, à imprensa, às máquinas e ao computador.

Haverá os que defenderão que a escola vem-se modernizando, e que hoje já utiliza, sim, recursos tecnológicos, como a TV e o vídeo, principalmente. Mas o cerne da questão reside na forma como tais recursos são utilizados. Colocar uma turma para ver um filme porque o professor faltou, ou pedir que, depois disso, os alunos respondam a um questionário fechado - certo ou errado - sobre as obviedades informativas que qualquer leitura apressada é capaz de apreender, definitivamente não pode ser considerado como «ver um filme».

Nos projetos anteriores, elaborados pela equipe de pesquisa, viabilizamos uma nova abordagem em desenvolvimento de habilidades de leitura (Villadi, 1997), aplicando, em seguida tal metodologia a obras de literatura infanto - juvenil, criando material didático específico, veiculado, num primeiro momento, apenas em veículo tradicional - papel (Villardi, 1998) e, posteriormente, em softwares educacionais (Villardi, 1999). Utilizamos um sistema didático-metodológico-computacional multidisciplinar, que viabilizasse o desenvolvimento das habilidades cognitivas a

\footnotetext{
${ }^{15}$ O termo - tal como formulado, na década de 60, por Umberto Eco, em Apocalittici e Integrati, que apresenta uma interessante leitura acerca dos rumos da civilização ocidental frente aos impactos tecnológicos e à cultura de massa - foi revisitado por Franco \& Sampaio no artigo $<<$ Linguagens, Comunicação e Cibercultura: Novas formas de produção do saber >>.

${ }^{16}$ Baudrillard, J. (1992) e (1997)

${ }^{17}$ Sfez, L. (1994)

${ }^{18}$ Franco \& Sampaio (1999) p. 5.
} 
partir do uso da linguagem em diferentes códigos, delineando uma proposta interativa que valorizasse a construção do conhecimento.

A partir do resultado dessa investigação foi possível:

D avaliar a contribuição do uso de recursos tecnológicos para o desenvolvimento de habilidades de leitura;

D constatar que o intercâmbio entre diferentes mídias se constitui num elemento que possibilita a elaboração de significados mais amplos, face a inserção numa cultura onde texto e imagem se alternam no cotidiano do aluno;

D verificar o impacto positivo da utilização de recursos da informática sobre o envolvimento dos alunos com a leitura;

D analisar algumas dificuldades dos professores no desenvolvimento lingüístico de seus alunos, no que se refere ao campo da leitura e da escrita, em especial, a dificuldade no desenvolvimento de habilidades de ler os significados não evidentes de um texto, o que refletirá na capacidade de «ler o mundo»;

D identificar a necessidade de projetos que atendessem à demanda por programas, cursos e metodologias que habilitassem o professor a lidar com os crescentes níveis de complexidade que o cenário educacional impõe.

A partir dessa experiência, surgiu a necessidade de expandir essa metodologia comprovadamente eficaz, para um maior número de professores da rede pública.

Para isso, nossas investigações anteriores revelaram a necessidade de investir na formação continuada de professores, de modo a torná-los aptos a atuar no trabalho com o desenvolvimento lingüístico de seus alunos, no que se refere ao campo da leitura e da escrita.

Como o acesso à variedade culta da língua se dá pela apropriação de estruturas lingüísticas complexas, que dependem do desenvolvimento de habilidades mentais de leitura ${ }^{19}$, é papel da escola fornecer ao aluno as condições para que tal apropriação ocorra. Uma vez desenvolvidas, o sujeito será capaz de ler qualquer tipo de texto e, conseqüentemente, ler o mundo, de forma crítica, construindo assim sua cidadania $^{20}$.

Investigando mecanismos que viabilizassem a utilização desse conhecimento diretamente na sala de aula, buscamos adequar a perspectiva teórico-metodológica adotada ao uso de novas tecnologias no ambiente escolar, desenvolvendo um sistema múltiplo em EAD, baseado no conceito de rede, a partir do qual sejam oferecidos cursos de educação continuada e de formação de professores (em nível póssecundário de graduação e de especialização) na área de linguagem.

\footnotetext{
${ }^{19}$ Saussure ( 1997)

${ }^{20}$ Foucambert ( 1999)
} 
Raquel Marques Villardi, Cleia Santos Rodrigues, Marta Cardoso de Lima da Costa Rego...

Viabilizamos o desenvolvimento das habilidades cognitivas através de um sistema didático-metodológico-computacional, que permitiu delinear uma proposta interativa de construção do conhecimento a partir do uso de diferentes códigos de linguagem.

Montamos nosso grupo de pesquisa nesse projeto de Educação à Distância, com profissionais de diversos campos: pedagogos, profissionais da área de multimídia, professores da área de Letras e Matemática para que a elaboração e construção do material didático, com metodologia de educação à distância pudesse atingir as diferentes características da clientela. Durante a preparação do material, foi fundamental objetivar as seguintes características:

Dlareza, do ponto de vista da linguagem;

D Comunicação imediata com o interlocutor;

D Interação entre o interlocutor e o material;

D Estímulo à troca de experiências com os colegas do curso.

Desenvolvemos um protótipo de mini-curso de formação continuada à distância na área de matemática, intitulado «O conceito de fração e a Educação infantil» e organizado em seis módulos:

D primeiro módulo apresenta cenas deflagradoras sobre o cotidiano da educação infantil, com o objetivo de fazer emergir algumas concepções dos alunos, segundo Giordan e Vecchi uma situação incitadora que provoca idéias dos alunos para depois e em trabalhos de grupo fazer com que as representações se encontrem e confrontem no diálogo dos bate-papos e fóruns.

D No segundo módulo, percebemos a amplitude do espaço geométrico e confrontamos novos contextos que permitem, conforme Giordan e Vecchi aprender com e contra as suas concepções prévias.

D No terceiro módulo, o aluno é apresentado a um ambiente topológico e métrico, espacial e plano de relações de equivalência e de ludicidade, que possibilitam alterações das concepções prévias a partir das operações mentais efetuadas nos fóruns.

D No quarto módulo, movimentos com figuras geométricas são analisados e vivenciados, é o espaço das transformações.

D No quinto módulo focalizamos atividades interdisciplinares que envolviam o conceito de fração.

D No último módulo fechamos o processo avaliativo que foi estruturado com base em dois eixos: cognitivo e participação interativa.

Através do mini curso, testamos a proposta que beneficiou 31 professores. Para disponibilizar o protótipo, utilizamos quatro máquinas do Laboratório de 
Uma perspectiva interacionista em educação à distância na área de linguagem

Informática da Faculdade de Educação da UERJ e seguimos um cronograma onde os alunos prosseguiam no curso à medida em que os módulos eram disponibilizados. Os inscritos que possuíam computador próprio receberam um CD-room com o mini-curso para que pudessem fazer o curso off-line em casa. Deveriam segui-lo seqüencialmente conforme o cronograma, para que quando fossem ao fórum, estivessem no mesmo nível de evolução no curso. A decisão de oferecer o curso em $\mathrm{CD}$ foi tomada pela equipe no momento em que foram verificadas dificuldades técnicas, tanto da ordem da acessibilidade da própria rede, quanto do fato de nem todos possuírem computadores conectados à internet.

Foi realizada uma pesquisa de campo por uma equipe multidisciplinar composta por sete bolsistas de pedagogia, um professor de matemática, um professor de letras e três bolsistas de informática, que resultou na construção de conhecimento teórico e prático, com a vivência dos fatos e não apenas suposições e especulações, num processo de reflexão-ação.

Com base em um estudo sobre a aplicabilidade e funcionalidade de cada uma das ferramentas de interação, concluímos quais deveriam ser utilizadas no curso. Definimos então, os fóruns como espaço de construção do conhecimento e troca de experiências, abrindo discussões sobre o tema, fundamentadas nas indagações propostas pelo professor autor do curso; as listas de discussão tornavam possível a comunicação com todo o grupo; os e-mails possibilitaram a comunicação individual aluno-tutor e salas de estudo, um espaço livre de interação entre todos os participantes. Escolhemos ferramentas de interação que facilitassem o aluno, como fóruns e e-mails em português, conseguidos na internet gratuitamente. Os alunos que fizeram o curso off-line acessavam a rede apenas para obter as ferramentas de interação no laboratório da faculdade.

Seis bolsistas do curso de pedagogia e professoras das séries iniciais do Ensino Fundamental, participaram do processo de formação do tutor, que foi dividido em três etapas: Na primeira, realizamos um estudo teórico metodológico, onde abordamos a função do tutor em um curso EAD, de modo a defini-lo não como um treinador, mas sim como educador. Na segunda etapa, que envolveu a participação no curso, desempenhando o papel de alunas, tivemos a possibilidade de fazer uma análise crítica do processo, que originou demandas por mudanças na navegabilidade e na comunicabilidade do curso e, resultou na definição de padrões de atuação que afirmassem a interação e comunicabilidade. Esse artifício fundamentou a ação do tutor como educador, estabelecendo métodos de mediação, interação e estímulo. Somente na terceira etapa, houve a atuação real das bolsistas como tutoras do curso.

A formação dos tutores foi realizada durante o teste de bancada, sendo o tutor o primeiro aluno do curso. $\mathrm{O}$ sentido da formação tutorial, nessa lógica, foi o de tentar identificar, minimizar e resolver possíveis problemas e dificuldades que seriam encontrados posteriormente, pelos alunos, quando o curso estivesse em 
Raquel Marques Villardi, Cleia Santos Rodrigues, Marta Cardoso de Lima da Costa Rego...

rede. Através desse procedimento, reformulamos e redimensionamos algumas propostas, buscando sempre a compreensão e comunicabilidade. Partindo do experimento com o grupo de tutores no teste de bancada, chegamos a conclusão de que era necessário um arquivo com normas gerais sobre o acesso ao mini-curso e a utilização das ferramentas de interação definidas.Esse arquivo foi colocado à disposição dos alunos no ato de inscrição.

Acreditamos que a formação do tutor é altamente relevante e é preciso que antes de agir como orientador da aprendizagem, ele vivencie o processo como aluno, que passe por todos os momentos e dificuldades que os alunos dos curso encontrarão, estando assim apto para esclarece-los ao máximo.

Foi criado um mecanismo de controle administrativo em que o professor e o tutor acompanhassem o desenvolvimento dos alunos, desde a inscrição até o término do curso. Esse mecanismo se constituía de um cadastro com informações gerais dos alunos, de forma que fosse possível localizá-los e contactá-los por outros meios além da internet, para consultá-los e dessa forma, saber se estavam conseguindo acessar o curso, realizar e enviar as atividades propostas.

Por último, construímos um sistema de avaliação e análise dos resultados, que mesclava a avaliação do professor - por meio dos trabalhos recebidos e da análise da participação de cada aluno nos espaços de interação -incluindo a autoavaliação e a avaliação dos colegas.

Os procedimentos metodológicos utilizados baseiam-se nos princípios da pesquisa-ação.

O objeto de nossa pesquisa é o desenvolvimento de um sistema didático metodológico-computacional para formação continuada à distância, portanto, todo fazer da equipe, desde o início do trabalho, tornou-se material relevante para nossa análise.

O curso, preparado pelo professor autor, foi, num primeiro momento, apresentado à equipe, viabilizando discussões e estudos sobre os padrões utilizados atualmente em diversos cursos de EAD, via Internet. A partir dos estudos, constatamos que nossa proposta significava um desafio pois chegamos à conclusão de que nosso trabalho não se identificava com os moldes de EAD encontrados, ainda vinculados aos padrões de instrução programada ou treinamento.

Três foram as frentes de atuação da equipe. Na primeira, os bolsistas de informática passaram a investir na elaboração da estrutura do curso, estudando diferentes programas, a fim de utilizar o que melhor atendesse às exigências de navegabilidade, otimização do tempo, permanência na rede e na perspectiva de busca da clareza e comunicabilidade. Nesta etapa, foi necessária uma interação com os bolsistas de pedagogia, promovendo a soma da dimensão pedagógica à técnica. 
Uma perspectiva interacionista em educação à distância na área de linguagem

Na segunda frente, o grupo de pedagogia ficou responsável pela definição de parâmetros de formação dos tutores do curso, que foram seis dos bolsistas dessa área. Na última frente, os membros da equipe, que atuam na área de linguagem, dedicaram-se a um estudo fundamentado não só no conceito de linguagem dentro do nosso protótipo, mas em EAD de forma geral. Esse estudo foi aprofundado e serviu de referencial teórico para a análise do curso. Essa análise se transpôs às revisões gramaticais de enunciados e propostas e alcançou questões como «nível de clareza» e «comunicabilidade» centradas no processo de comunicação do ponto de vista do receptor e não apenas do emissor.

Como resultado preliminar, citamos a necessidade de construção de uma rede de interação. $\mathrm{O}$ trabalho, dentro de uma equipe multidisciplinar com pessoas das áreas de Educação, Letras e Informática, onde várias as etapas do processo foram planejadas e experimentadas, gerou um ambiente de aprendizagem onde foi relevante o tanto que um aprendeu com o outro. Isto confirmou nossa hipótese acerca da necessidade de interação para a construção do conhecimento já nos primeiros momentos do processo.

A partir da amostragem deste curso, foi possível atestar que o nível de acessibilidade à rede ainda se encontra abaixo das expectativas, devido às dificuldades manifestadas por todos os participantes do curso, inclusive os tutores. Ao longo do curso, motivos como: não possuir o conhecimento mínimo de informática exigido (apesar de o declararem no momento da inscrição); dificuldades relativas ao conteúdo do curso proposto; problemas de acesso ou navegação na rede; disponibilidade de tempo para cumprir os prazos exigidos pelo curso configuraram um quadro de alto índice de evasão dos alunos. O papel do tutor, fundamental e determinante em todo processo, remete aos sentimentos de confiança e segurança, adquiridos durante o processo de formação e necessários ao embasamento de sua atuação no curso e a possibilidade de intervenção na proposta do professor-autor. $\mathrm{O}$ tutor tornou-se fundamental pois representou um diferencial no processo de construção do conhecimento.

Nossas pesquisas haviam verificado experiências sobre a atuação dos tutores que ainda ficavam atreladas aos modelos de instrução programada. Na nossa proposta de formação, objetivamos a garantia de um desempenho que foi fundamental tanto no acompanhamento dos alunos, quanto na efetivação da compreensão e comunicabilidade em todo o processo.

Não se pode dispensar o fato de que os tutores devem ser, essencialmente, os primeiros alunos do curso, participando como co-autores, vivenciando o processo de construção do protótipo para atuar como mediadores, criando um ambiente de interação compreendido como processo de afetação mútua. Nesse sistema múltiplo computacional, garantimos o sucesso do curso proposto, com a construção coletiva da aprendizagem para os alunos que o concluíram. Estamos em processo de análise dos dados obtidos, para posterior elaboração de gráficos e tabelas que 
Raquel Marques Villardi, Cleia Santos Rodrigues, Marta Cardoso de Lima da Costa Rego...

nos permitam consolidar nossas hipóteses acerca da importância da formação e atuação dos tutores nos cursos de educação à distância.

À luz dos dados obtidos, podemos afirmar ser possível oferecer educação à distância, com uso de tecnologia, que se diferencie das propostas de instrução programada de treinamento à distância. Confirmamos a possibilidade de aprendizado à distância, em interação com outros, com autonomia, independentemente da relação espaço-tempo. Tal constatação nos proporciona maiores possibilidades de alcançar o corpo docente da rede pública, no que diz respeito à formação continuada, na busca de uma ação pedagógica eficaz, na área da linguagem, que rompa as fronteiras das limitações físicas e metodológicas da escola. 
Uma perspectiva interacionista em educação à distância na área de linguagem

\section{REFERÊNCIAS BIBILOGRÁFICAS}

Baudrillard, Jean. (1992). A transparência do mal. Campinas: Papirus.

Castro, Maria Helena Guimarães De., (org) (1999). Situação da educação básica no Brasil. Brasília: Instituto Nacional de Estudos e Pesquisas Educacionais.

Coll, CÉsAR et alli. (1996). O Construtivismo na Sala de Aula. São Paulo: Ática.

Eco, Humberto. (1976). Apocalípticos e Integrados. 2 ed. São Paulo: Perspectiva

Ferreiro, Emília \& TEBEROSKY, Ana. (1986) Psicogênese da Língua Escrita. Porto Alegre: Artes Médicas.

Ferreiro, Emília.(1990). A Escrita Antes das Letras. In SINCLAIR, Hermine (org.). A produção de notações na criança: linguagem, número, ritmos e melodias. São Paulo: Cortez Editora.

Ferreiro, Emília. (1992). Com Todas as Letras. São Paulo: Cortez Editora.

Ferreiro, Emilia. (2001). Cultura Escrita e Educação. Porto Alegre: Artmed Editora.

Foucambert, Jean. (1994). A Leitura em Questão. Porto Alegre: Artes Médicas.

Franco, Marcelo ARaúJo \& SAMPAIO, CARMEM SANChES. «Linguagens, Comunicação e Cibercultura: novas formas de produção do saber». In: Revista Informática na Educação,5. Campinas,Unicamp,junhode1999. OnLine: http://www.revista.unicamp.br/navegação/index.html

GARCÍA ARETIO, L. (1994). Educación a distancia hoy. Madrid, UNED.

IsER, A. (1999). Teoria da Ficção - Indagações à obra de Wolfgang Iser. Rio de Janeiro:EDUERJ.

Kaufman, Ana M. \& Rodrigues, Maria E. (1995). Escola, Leitura e Produção de Textos. Porto Alegre: Artes Médicas.

Kleiman, Angela. (1993). Oficina de leitura: teoria e prática. Campinas, Pontes (UNICAMP).

Landim, Cláudia. (1997). O que é Educação à Distância. Belo Horizonte, Miguilim.

LÉVY, PIERRE. As Tecnologias da Inteligência: o futuro do pensamento na área da informática. São Paulo: Editora 34

Oliveira, Marta KoHL DE. (1995). Vygotsky, aprendizagem e desenvolvimento, um processo sóciohistórico. $2^{\mathrm{a}}$ edição, São Paulo: Scipione.

RodrígueZ, E; QuinTILLAN, M. (1999). La Educación a Distancia en tempos de cambios: - Nuevas generaciones, viejos conflictos. Madrid: Ediciones de La Torre.

SAussure, F. (1969). Curso de Lingüística Geral. São Paulo: CULTRIX.

SHERRY, L. «Issnes in distance learning» In: International Journal of Distance Education, Aug, 1999. Online: http://www.cudenver.edu/public/education/edschool/issnes.html

Sfez, Lucian.(1994). Crítica da Comunicação. São Paulo: Loyola.

VILLARDI, RAQUEL MARQues (2001). Escola e infância : a sacralização do olhar enviesado ou ainda há vida nos porões. Revista Polêmica. Rio de Janeiro,v.3, p.31-42.

Villardi, Raquel Marques. (2001). Formação de leitores. Estratégias para uma metodologia do gosto. Palavra, Lisboa, v.20, p.43-52.

Villardi, Raquel Marques, silveira, Elizabeth. (2000). A autoridade do Discurso do Mestre ou de Costas para a Cidadania. Palavra, Lisboa, v.17, p. 45-52.

Villardi, Raquel Marques, Oliveira, Carlos Alberto De. (2000)..A política de Educação à Distância e a Profissionalização: desafios. Revista de Administração Educacional, Recife, v.2, n.6, p.37-47. 
Raquel Marques Villardi, Cleia Santos Rodrigues, Marta Cardoso de Lima da Costa Rego...

Villardi, Raquel Marques. (1998). Ensinar a gostar de Ler: Discutindo Estratégias para a Formação de Leitores. Tecnologia Educacional, Rio de Janeiro, v.26, n.142, p.12-17.

Villardi, Raquel Marques. Literatura Infanto_Juvenil: Ser ou Não Ser. Doce de Letra, v>5, p1-12.

Villardi, Raquel Marques, Silveira, Elizabeth. (1996). Aprendendo a Gostar de Ler e Aprendendo a Gostar de Escrever: Uma Experiência Inovadora. Doce de Letra, v.10, p.1-8.

VILLARDI, RAQUEL \& SENNA, LUIZ ANTONIO GOMES. (1999). Literatura na escola: por uma metodologia do desenvolvimento do gosto. Atas do 12. COLE. Campinas, Associação de Leitura do Brasil. (meio digital)

Villardi, Raquel. \& Silveira, E.(1998). Linguagem na escola: desenvolvimento de habilidades linguisticas com softwares educacionais. Atas do Workshop de Acompanhamento e Avaliação da FINEP.Rio de Janeiro,FINEP. p.15-18.

Vygotsky, Lev. (1989). A formação Social da Mente. $3^{\text {a }}$ edição, São Paulo: MartinsFontes.

Vygostsky, LeV . (1998). Pensamento e Linguagem. São Paulo: Martins Fontes.

PERFIL ACADÉMICO Y PROFESIONAL DE LOS AUTORES

Raquel Marques Villardi. Professora Doutora. Universidade do Estado do Rio de Janeiro. Programa de Pós-graduação em Educação. Núcleo de Pesquisa Linguagem e Processos Educacionais. Coordenadora do Projeto de Pesquisa. $\underline{\text { Rvillardi@yahoo.com.br }}$

Cleia Santos Rodrigues. Pedagoga. Bolsista de Apoio Técnico. Cleia Rodrigues@hotmail.com

Marta Cardoso de Lima da Costa Rego. Pedagoga. Mestranda. martalimarego@hotmail.com

Cristiane Fallah de Aguilar. Pedagogia. Bolsista de Iniciação Científica. toffe@osite.com.br

Daniel do Vale Gonçalves Pereira. Informática. Bolsista de Iniciação Científica. lpeartree@uol.com.br

Thiago Lopes Schettini. Informática. Bolsista de Iniciação Científica. thiagoschettini@hotmail.com

Juliana Maria Alves de Carvalho. Letras. Bolsista de Iniciação à Docência. juliensorelbr@yahoo.es

Ester Oliveira. Letras. Bolsista de Iniciação à Docência. la graciosidad@yahoo.com.br 